\title{
Studies on the Mechanism of Starch Granule Formation in Plastids
}

\author{
By Kenji Dor and Aкemi Dor \\ Institute of Scientific and Industrial Research, Osaka University, Suita, Osaka.
}

\begin{abstract}
A model experiment was performed to simulate the process of precipitation of starch molecules in plastids. This suggested the presence of a soluble form of ADP-glucose $\alpha-1,4-$ glucan- $\alpha$-4-glucosyltransferase (starch synthetase) in spinach chloroplasts. The enzyme was purified in order to use it as chain elongator in a system for starch granule formation in vitro, which is to be constructed by well-characterized enzymes. It was found that the spinach enzyme catalyzes the formation of a long chain of $\alpha-1,4$-linked glucose units.
\end{abstract}

\section{Introduction}

We have now a great deal of knowledge on the enzymes which apparently are involved in the metabolism of starch. Many of them are obtainable as a highly purified form and their modes of action on starch molecules in vitro are rather well characterized. However details of the mechanism of starch granule formation in plastids of plant cells are not as yet fully understood and combinations of the wellcharacterized enzymes to form starch granules in vitro have not been tried with success.

The mechanism of starch granule formation in plastids may be considered as consisting of the following steps: (1) appearance of glucose donor(s) and primer(s); (2) chain lengthening by $\alpha$-1,4-glucosidic bond formation and introduction of branching by $\alpha-1,6$-glucosidic bond formation; (3) precipitation of preformed starchy macromolecules. In higher plants the main glucose donor is believed to be ADP-glucose. Accumulation of ADP-glucose in illuminated chloroplasts may be predicted on the basis of the accelerated action of ADPG-pyrophosphorylase ${ }^{1}$, which is known to be present in the organelles. Considering the homopolymeric nature of starch molecules, members of maltooligosaccharides may be considered as possible primers to accept glucose from the donor ADPG, although experimental evidences for their proposed role are lacking. As regards with the steps (2) and (3), these have been the main concern of the authors, because full understanding of the steps will lead to understanding the mechanism of formation of two distinct molecular species, incorporated into a granule, a phenomenon which distinguishes the biosynthesis of starch from that of glycogen, and which represents an expression of a genetic state of the plant. At present it is believed that chain lengthening is catalyzed by ADPGstarch synthetase and chain branching is introduced by the action of so-called branching enzymes. Combined action of highly purified preaparations of these enzymes under as yet unknown conditions will lead to a reproduction of the essential features of the process of starch granule formation in vivo.

In this paper the authors describe some experiments on the precipitation of starch in proteinous gel, and on the chain lengthening capacity of ADPG-starch synthetase 
of spinach. Both works consititute a part of an attempt at constructing a starch granule-synthesizing system consisting of well-characterized components. Because it is known that isolated spinach chloroplasts synthesize starch from carbon dioxide under illumination, it is expected that they are a material of choice for isolating such components.

\section{Precipitation of Starch in Gelatin Jelly}

Precipitation of newly-synthesized starch molecules would constitute the last step in the process of starch granule formation in plastids. Since no detectable amount of starch has been found in soluble form in plastids, it might be supposed that there are some agency to precipitate the polymer highly effectively in the organelles. The true nature of such an agency has not been determined, but on the basis of the observation that presence of an appropriate amount of gelatin causes effective precipitation of starch from aqueous solution it might be imagined that a high concentration of proteinous material in plastids be among candidates for such an agency. In the following description attention is mainly directed to amylopectin as starchy material, because it constitutes the main component of starch.

1) A ternary amylopectin-gelatin-water system

In Fig. 1 is illustrated a sort of phase diagram of a system consisting of potato amylopectin, ossein gelatin and water. ${ }^{2)}$ It can be seen that in this system phase separation will be far more frequently encountered than a homogeneous mixture. Phase separation is also observed with a system egg white albumin-potato amylopectin-water. Because plastids are rich in proteins, a speculation is that there is a strong tendency for newly synthesized starch molecules to form a separate phase in the organelles.

2) Polycrystalline amylopectin granules

In plastids starch always takes a polycrystalline granular form. In the presence of high concentration of gelatin, amylopectin precipitates as polycrystalline granules* almost quantitatively, although the crystallinity is not so high as to exhibit polarization crosses under crossed Nicols. In Fig. 2) X-ray diffraction powder patterns and photopastegrams of the amylopectin granules "crystallized" at different temperatures are shown. It can be seen that at a higher temperature granules with a crystalline pattern close to " $\mathrm{A}$ " type and a higher melting point is obtained, thus a phenomenon observed in vivo being paralleled in vitro. ${ }^{2}$ ) By adding an appropriate amount of gelatin to a mixture of amylose and amylopectin, polycrystalline granules are also obtained in which the two polymers are contained in the same proportion as the starting mixture.4)

3) Electron microscopic observations by other investigators

* Considering the highly ramified structure of amylopectin molecules, it is rather striking that it is always present in a crystalline form in nature. Although a polycrystalline preparation of waxy rice amylopectin was obtained by Dr. T. J. Schoch by careful precipitation of the amylopectin with methanol, ${ }^{3)}$ it seems important to the authors to obtain crystalline amylopectin granules under conditions not far removed from physiological ones. 

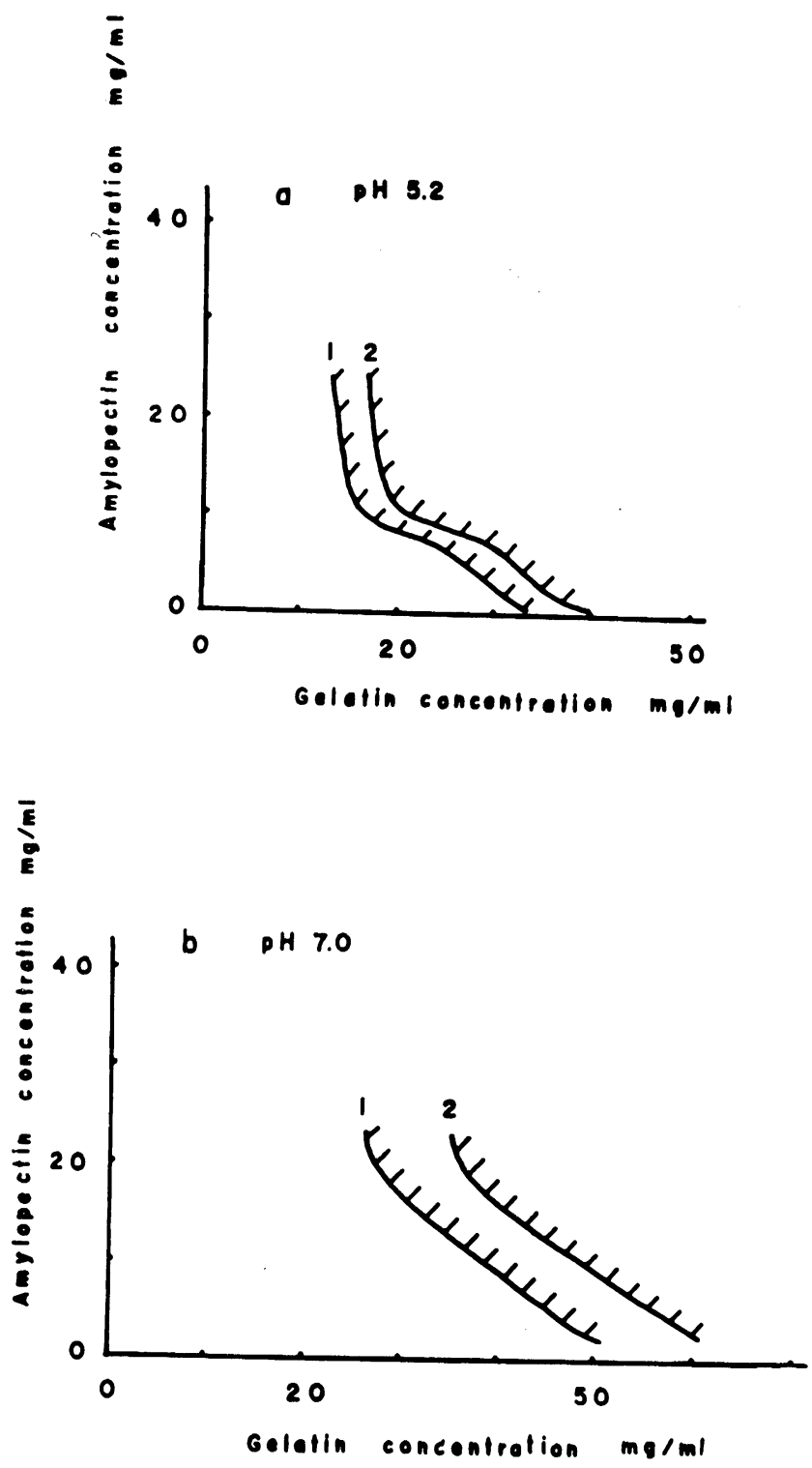

Fig. 1. The precipitation lines of the potato amylopectin-ossein gelatin-

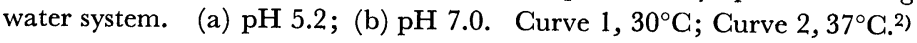

If the assumption is correct that after being synthesized, the starch molecules are present in a transient soluble state, and then incorporated into a granule, such a state may be detected chemically or by alternative techniques. No appreciable amount of starch precursors has been found in plant materials, but electron microscopy has suggested the presence of a substance which will later be incorporated into a starch granule. ${ }^{5}$ 
Fig. 2. (a)
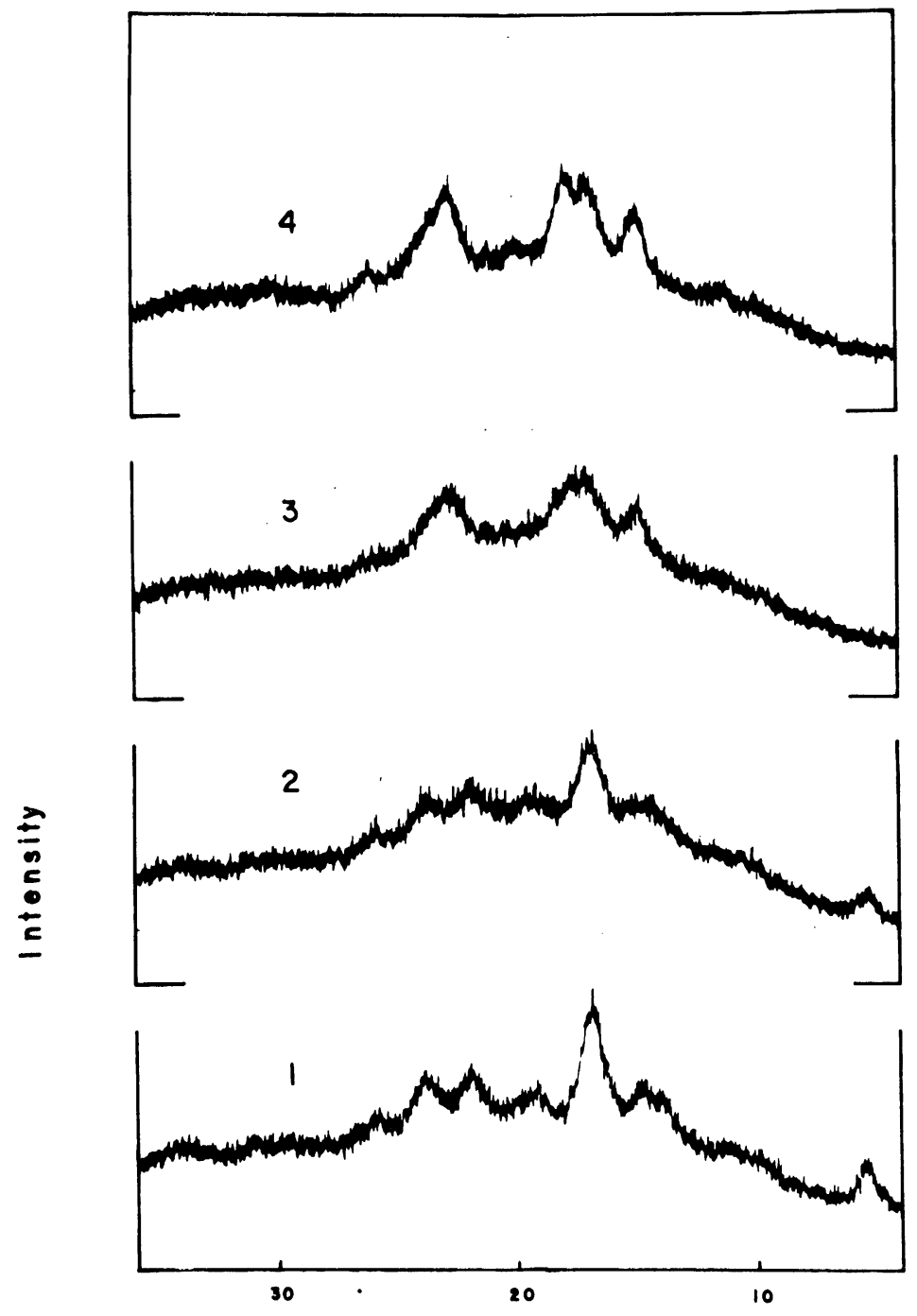

Fig. 2. (b)

$2 \theta(\circ)$

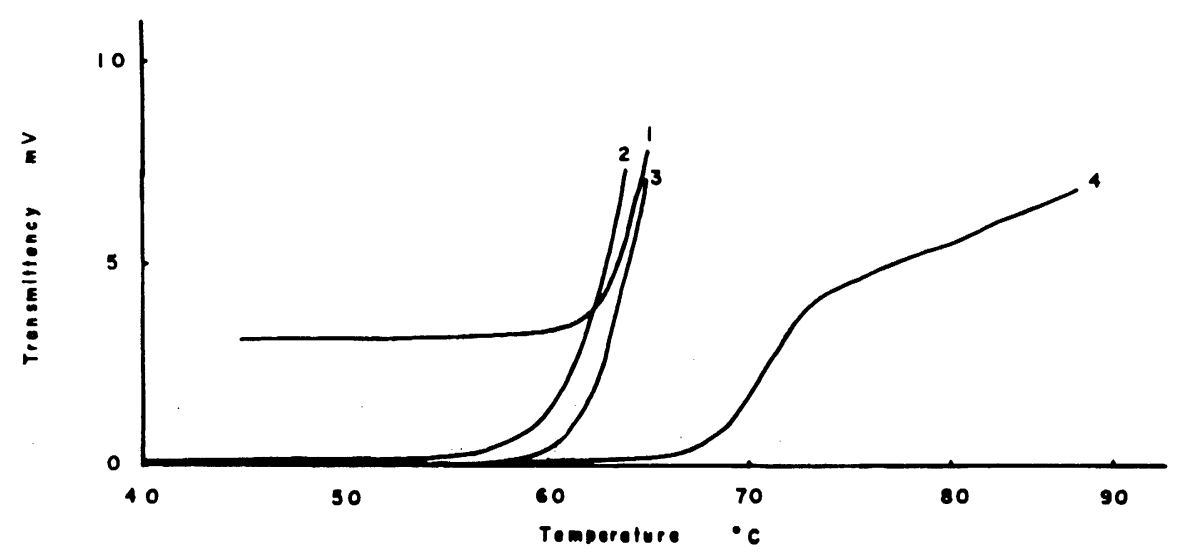




\section{Preparation of Amylopectin-Enzyme Complex as a Granule}

It follows as a necessity, from the assumption outlined above, that enzymes responsible for synthesis of starch molecules play their roles in a soluble state. In 1960-61 Leloir and co-workers reported the properties of ADPG(UDPG)-starch synthetase firmly bound to starch granules. ${ }^{6,7,8)}$ It is difficult to solubilize the enzyme from the granule without disruption of the latter. $\left.{ }^{9}\right)$

The process of formation of such an enzyme-starch complex may be imagined as follows: After the completion of catalytic action of the enzyme its soluble complex with the product precipitates along with abundant product molecules to form a granule, and thereafter the enzyme is left to be confined within it. The process may be simulated in vitro by formation of starch granules, to which a starchsynthesizing enzyme is firmly bound, in a starch-enzyme-gelatin system.

From a system amylopectin- $a$-glucan phosphorylase-gelatin system, a granular amylopectin preparation is obtained, which after thorough washing incorporates ${ }^{14} \mathrm{C}$-glucose when incubated with ${ }^{14} \mathrm{C}$-glucose 1 -phosphate. ${ }^{10)}$ When an extract of spinach chloroplasts is used as enzyme, the amylopectin preparation incorporates ${ }^{14} \mathrm{C}$ glucose with concomitant liberation of $\mathrm{ADP}$ on incubation with $\mathrm{ADP}-{ }^{14} \mathrm{C}$-glucose ${ }^{11}$ ) In fact this was the first indication that a soluble ADPG-starch synthetase is present in spinach chloroplasts.*

\section{Purification and the Polymer-forming Capacity of Spinach ADPG-Starch Synthetase}

It is known that isolated chloroplasts retain their capacity for synthesizing starch molecules. Hence, it will be advantageous to construct a system for starch granule formation in vitro using enzymes isolated from spinach chloroplasts, because it will be readily known to what extent the system represents the events occurring in vivo.

Spinach leaves contain ADPG-starch synthetase almost in a soluble form, and the partially purified preparations are readily obtained from the plant material purchased from a local market. But the enzyme content is so low (assuming that the specific activity of the enzyme is about $50 \mu \mathrm{moles} / \mathrm{min} / \mathrm{mg}$ protein, its content in spinach leaves is estimated to be less than $1 \mathrm{mg} / \mathrm{kg}$ fresh weight) that it is difficult to

\footnotetext{
* Soluble phytoglycogen synthetase had been found in sweet corn grains by Cardini et al. ${ }^{12}$ ) as the enzyme responsible for phytoglycogen biosynthesis. Our observation revealed the presence of a soluble enzyme of the same class in an organ in which starch is present as sole known reserve polysaccharide.
}

Fig. 2. (a) X-ray diffraction patterns of amylopectin granules. Curve 1, commercial potato starch (water content 19\%); Curve 2, potato amylopectin (water content $17 \%$ ) crystallized at $4^{\circ} \mathrm{C}$ for 10 days at a gelatin (non-deionized calfskin) concentration of $50 \%$; Curve 3, potato amylopectin (water content $15 \%$ ) crystallized at $37^{\circ} \mathrm{C}$ for 10 days at a gelatin (non-deionized calfskin) concentra tion of $50 \%$; Curve 4, corn starch (water content 16\%) prepared in the laboratory. Other details as described previously. ${ }^{2}$ )

(b) Photopastegram of amylopectin granules Numbers 1, 2, 3 and 4 correspond to the same samples as in (a). Details as given previously. ${ }^{2)}$ 
obtain a purified preparation in quantities enough to investigate the physico-chemical properties of the enzyme. Therefore the authors' concern is at present with its capacity for catalyzing the formation of high polymers.

\section{1) A partially purified preparation from isolated spinach chloroplasts}

Chloroplasts are isolated from spinach leaves in $0.35 \mathrm{M} \mathrm{NaCl}$. The enzyme is extracted from the chloroplasts with dilute buffer and purified by fractionation with $\left(\mathrm{NH}_{4}\right)_{2} \mathrm{SO}_{4}$, adsorption on and desorption from calcium hydroxylapatite, and chromatography on DEAE-cellulose. The purification procedure is summarized in Table I. ${ }^{13}$ )

Table I. Purification of ADPG-Starch Synthetase

\begin{tabular}{l|c|c|c|c|c}
\hline \multicolumn{1}{c|}{ Fraction } & $\begin{array}{c}\text { Total } \\
\text { vol. } \\
(\mathrm{ml})\end{array}$ & $\begin{array}{c}\text { Total } \\
\text { activity } \\
\text { (units) }\end{array}$ & $\begin{array}{c}\text { Total } \\
\text { protein } \\
(\mathrm{mg})\end{array}$ & $\begin{array}{c}\text { Specific activity } \\
\text { (units per mg } \\
\text { of protein) }\end{array}$ & $\begin{array}{c}\text { Recovery } \\
(\%)\end{array}$ \\
\hline $100,000 \times g$ supernatant of crude extract & 214 & 984 & 3360 & 0.29 & 100 \\
$\left(\mathrm{NH}_{4}\right)_{2} \mathrm{SO}_{4}$ ppt. (0.2-0.4 sat.; pH 7) & 17.4 & 730 & 623 & 1.17 & 74 \\
Calcium phosphate-gel eluate & 61 & 570 & 82 & 6.61 & 58 \\
$\left(\mathrm{NH}_{4}\right)_{2} \mathrm{SO}_{4}$ ppt. (0-0.5 sat.; $\mathrm{pH} \mathrm{7)}$ & 5 & 450 & 53 & 8.41 & 46 \\
DEAE-cellulose eluate & 30 & 129 & 6.8 & 18.97 & 13 \\
\hline
\end{tabular}

On incubation with ADPG and the appropriate primers, apparently irreversible incorporation into the latter of glucose moiety of the former occurs with concomitant liberation of ADP. The amount of incorporated glucose exactly corresponds to that of liberated ADP, and the glucose residues are added to the non-reducing ends of a primer molecule by $a-1,4$ glucosidic bond formation. Thus the reaction catalyzed by the enzyme can be represented in the following formula;

$$
\mathrm{ADPG}+\text { primer } \longrightarrow \text { primer-glucose }+\mathrm{ADP}
$$

This is exactly of the same type as that formulated for the reaction catalyzed by starch granule-bound enzymes, except that in the latter case the primer reacts in a solid state.

With the high polymer forming capacity of the enzyme at this stage of purification, a somewhat peculiar result was early observed, ${ }^{13)}$ which led the authors to suppose that the chain-elongation by this enzyme might have a certain limitation. Considering that even a trace of amylase may have serious interference, further purification of the spinach enzyme has been attempted.

\section{2) Further purification of the enzyme}

To remove contaminating amylase(s) as far as possible from the enzymic preparation, an additional purification step consisting of a chromatography on amylopectin-impregnated cellulose is introduced on the basis of a high affinity of the enzyme to substrate amylopectin, which, in turn, has affinity to cellulose. This step has proved to be highly effective to remove bulk of inert proteins as well as amylase(s). An example of the chromatography is shown in Fig. 3. The pooled fractions 


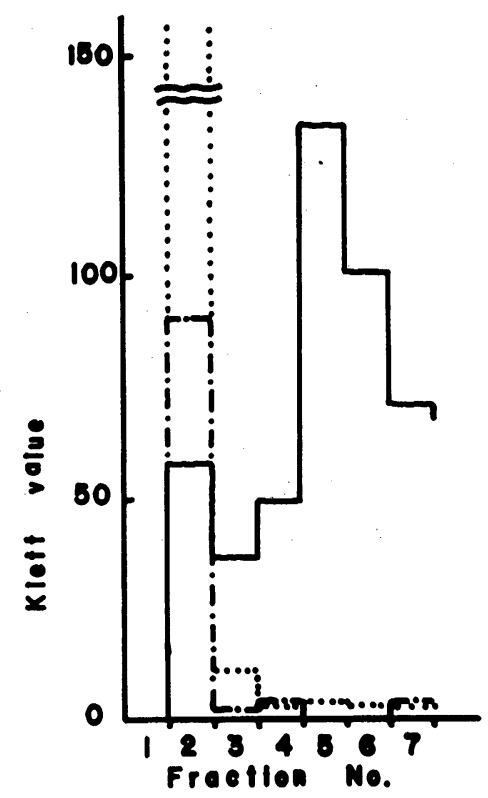

Fig. 3. Elution pattern of the spinach starch synthetase on a cellulose column impregnated with amylopectin. The synthetase (80 units, $3 \mathrm{ml}$ ) was put onto the top of a column $(1 \mathrm{~cm} \times 10 \mathrm{~cm})$ of cellulose impregated with potato amylopectin, which had been equilibrated with $0.005 \mathrm{M}$ phosphate-0.001 M EDTA ( $\mathrm{pH} 7.5$ ), and eluted with the same buffer at a flow rate of $0.2 \mathrm{ml} / \mathrm{min}$ at $4^{\circ} \mathrm{C}$. Fractions $(8 \mathrm{ml})$ were collected and assayed for synthetase and amylase $(\mathrm{s})$. — described previously. ${ }^{14}$ )

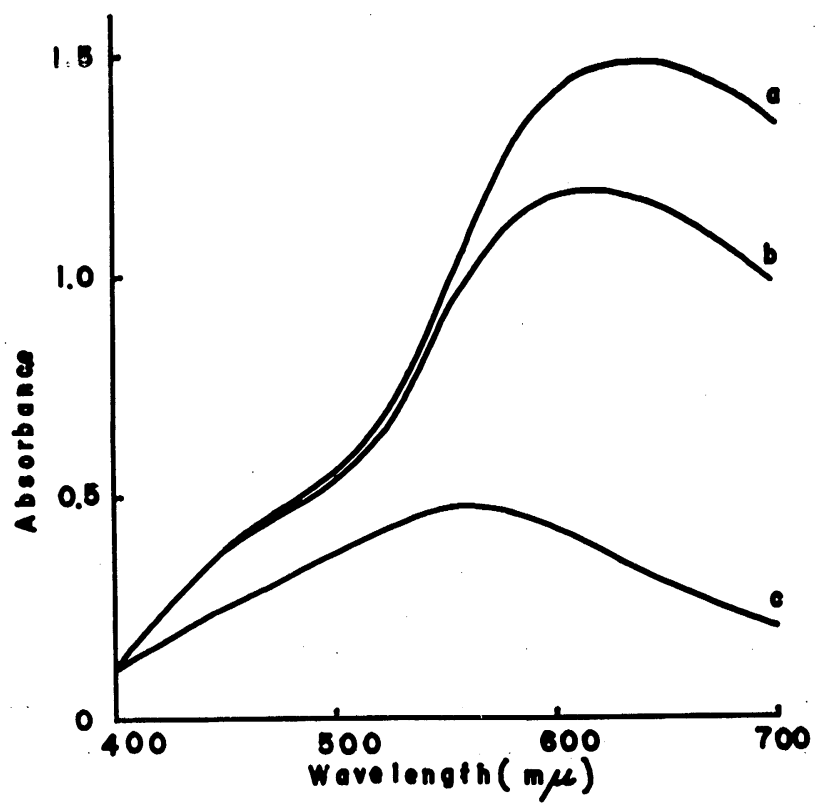

Fig. 4. Absorption curve of the polymeric product. Polymers were stained with iodinepotassium iodide. a, potato amylose; $b$, polymeric product; $c$, potato amylopectin. ${ }^{14}$ ) 
obtained have a specific activity around $30 \mu \mathrm{moles} / \mathrm{min} / \mathrm{mg}$ protein under the standard assay conditions. Unfortunately, the purified enzyme is very labile and it has not been successful to reduce the volume of the preparation with retention of the high specific activity. But purified enzyme, after concentration, can be used in an attempt to lengthening the outer chains of the primer molecule greatly.

On incubation of ADPG and a small amount of amylopectin as primer with the enzyme the reaction mixture soon becomes cloudy and a formation of the flocculent precipitate is eventually observed. The precipitates stains blue with $\mathrm{I}_{2}$-KI solution (Fig. 4) and analysis suggests that a preparation of such precipitate is composed of amylopectin molecules, to each of the non-reducing ends of which is attached a chain of $a-1,4$-linked glucose units of DP of about 170.14) From this result it can be concluded that the upper limit, if any, of chain-elongation under catalysis of this enzyme should be in a region of far greater DP than that prematurely supposed with the partially purified preparations.

\section{Discussion}

As described above, model experiments for formation of starch granules in a proteinous material suggested the presence of a soluble form of ADPG-starch synthetase in spinach chloroplasts. Exactly speaking, the identity of the soluble and the starch granule-bound enzymes of this class has not been established. The fact that the latter obtained from storage organs of plant materials are able to utilize UDPG as a glucose donor is a basis for suggestion that different enzymes are being dealt with. But the starch granule-bound enzyme from leaves or chloroplasts seems to use ADPG as the sole glucose donor and an interesting observation of Cardini et al. ${ }^{9}$ ) that on disruption of starch granules the affinity of the enzyme to UDPG is essentially lost seems to support the alternative interpretation that the two forms only represents the different states of the same enzyme.

It is now demonstrated that the purified spinach enzyme catalyzed the formation of a long chain of $a$-1,4-linked glucose units in the presence of an appropriate primer. This capacity seems to be the prerequisite for the enzyme to replace $a$ glucan phosphorylase as natural chain elongator. Thus the spinach enzyme is full of promise for use as one of the main components of an in vitro system for formation of starch granules.

As mentioned in Introduction, starch granule formation is a tissue specific biological phenomenon, in the sense that in waxy mutants waxy starch appears only in pollen grains and endosperm tissues. Investigation into its mechanism will reveal an as yet unknown mode of expression of a genetic character, probably including an interaction between the informations held in DNA of the nucleus and those held or expressed in the self-replicating organelles, plastids. An in vitro system to be constructed by spinach enzymes will prove to be an important aid in such an investigation. 


\section{References}

1) Ghosh, H. P. and Preiss, J., J. Biol. Chem., 240, 960 (1965).

2) Doi, K., Biochim. Biophys. Acta, 94, 557 (1965).

3) Schoch, T. J. and French, D., Cereal Chem., 24, 231 (1947).

4) Doi K. and Nikuni, Z., Stärke, 14, 461 (1962).

5) Badenhuizen, N. P., Stärke, 15, 237 (1963).

6) De Fekete, M. A. R., Leloir, L. F. and Cardini, C. E., Nature, 187, 918 (1960).

7) Leloir, L. F., De Fekete, M. A. R. and Cardini, C. E., J. Biol. Chem., 236, 636 (1961).

8) Recondo, E. and Leloir, L. F., Biochem. Biophys. Res. Communs., 6, 85 (1961).

9) Frydman, R. B. and Cardini, C. J. E., Biol. Chem., 242, 312 (1967).

10) Nikuni, Z., Doi, A. and Doi, K., Abstracts, Sixth International Congress of Biochemistry, 1964.

11) Doi, A., Thesis, M. A. at Osaka University (1964).

12) Frydman, R. B. and Cardini, C. E., Biochem. Biophys. Res. Communs., 17, 407 (1964).

13) Doi, A., Doi, K. and Nikuni, Z. Biochim. Biophys. Acta, 113, 312 (1966).

14) Doi, A., Biochim. Biophys. Acta, 146, 603 (1967). 